\title{
Factors Associated with Depression among Chinese College Students
}

\author{
Jie Zhang ${ }^{1,2^{*}}$, Yiwen Zhang ${ }^{1}$, Yujie Tuo ${ }^{1}$ and David Lester ${ }^{3}$
}

${ }^{1}$ School of Social Development, Central University of Finance and Economics, Beijing, China

${ }^{2}$ Department of Sociology, State University of New York at Buffalo, Buffalo, New York, USA

${ }^{3}$ Stockton University, Galloway, NJ, USA

*Corresponding author: Jie Zhang, Department of Sociology, State University of New York at Buffalo, Buffalo, New York, USA, Tel: 716-645-2417; E-mail: zhangj@buffalostate.edu

Received date: August 31, 2018; Accepted date: September 15, 2018; Published date: September 29, 2018

Copyright: (C) 2018 Zhang $\mathrm{J}$ et al. This is an open-access article distributed under the terms of the Creative Commons Attribution License, which permits unrestricted use, distribution, and reproduction in any medium, provided the original author and source are credited.

\begin{abstract}
The present study was designed to examine the correlates of depression in college students in China, using the self-report Center for Epidemiological Studies-Depression Scale (CES-D). Students with religious beliefs were more likely to be depressed, while a positive life attitude, satisfaction with their major, and social support were negatively associated with lower levels of depression. These findings may help college counseling centers identify college students at risk for depression and other psychiatric problems, including suicidal behavior.
\end{abstract}

Keywords: Depression; Chinese students; Religious beliefs; Social support

\section{Introduction}

Mental health problems are a growing issue for college students, with the most common disorders being depression, anxiety, alcohol abuse, eating disorders, self-injury, and suicide attempts [1]. Among those disorders, depression is the leading problem for college students, and suicide is the second-leading cause of death among college students [2]. According to data published by the American College Health Association-National College Health Assessment [3], 30\% of college students reported that they were feeling "so depressed that it was difficult to function" at some time in the past year. In China, as reported by Beijing Suicide Research and Prevention Center in 2012, about 287,000 people die by suicide every year, and 70 percent of these suicides are experiencing depression. Depression debilitates people physically and psychologically, and depression was predicted to be the second leading cause of disability in 2020 by the WHO [4].

College students, a group of young people with high levels of motivation and intelligence, are at a critical time in their life, choosing and training for a career. Depression seriously impairs their performance, affecting their physical, emotional, cognitive, and interpersonal functioning [5]. Depressive symptoms undermine time management, problem solving and decision-making skills [6] and impact negatively on their memory and academic performance [7]. The present study explored correlates of college student depression.

There have been many studies of the correlates and predictors of depression in college students. Levels of depression vary with age [8], gender [9], life experiences, and personality traits [10]. Psychiatric and behavioral problems in family members, especially parents, can also increase the risk of depression. Changes in the family environment due to parental depression increase the risk of depression and suicide in children and adolescents [11].

In recent years, especially after China's economic reforms, the incidence of depressive disorders in Chinese youth has increased.
Suicide became the second leading cause of adolescent death in the 1990s [12]. The stress level of Chinese college students was found in one study to be higher than the stress levels of Korean and Japanese students [13]. Some commentators view the cultural transition taking place in China as the cause of the increase in depression in Chinese adolescents [14].

Previous research in the United States has found that the level of depression is higher in those with poor social support and with lower levels of life satisfaction. A low frequency of interaction with one's friends and parents, and the experience of loneliness were significant factors in a multivariate model predicting depression [15]. For Chinese students, social support may enhance the students' esteem and alleviate depression [16]. Life attitudes also exert an influence on mental health [17]. People with low levels of life satisfaction are more susceptible to depression, while those with high level of life satisfaction find it much easier to experience happiness, and they are less likely to experience depression [18]. The present study was designed to see if these associations could be replicated in a Chinese college sample.

\section{Material and Method}

\section{Participants}

A questionnaire was administered at a four-year university in Beijing, China, in the Fall Semester of 2012. A total of 1,298 students (61.6\% female and $39.4 \%$ male), evenly sampled from all the four years of undergraduate study, participated in this survey. The sample matched the gender ratio of the student body of the university. The mean age of the sample was $19.52(\mathrm{SD}=1.68)$.

Random sampling was used for this survey. The student roster for the university was exported into an SPSS program which was used to generate a random sample of students. The University Student Personnel Department helped the researchers contact the students who were then invited to meeting rooms to take the questionnaire. Informed consent was obtained from the students who were informed that they had the right to refuse and to quit the survey whenever they want. The study was approved by the university IRB. 
Page 2 of 4

\section{Measures}

Depression was assessed with the Center for Epidemiological Studies-Depression Scale (CES-D) [19] which consists of 20 items such as "I always feel lonely" or "I feel depressed." Respondents noted the number of days in the past week that the symptom was experienced and coded as 0 (no days) to 7 (7 days). The highest possible score on the CES-D is 140, with a higher score indicating a higher level of depression. The mean CES-D for sample was 32.43 ( $\mathrm{SD}=18.32$ ). Cronbach alpha for the present sample was 0.93 .

Social support was measured with Multidimensional Scale of Perceived Social Support (MSPSS) [20] which has been shown to be a valid and reliable measure for Chinese respondents [21]. The scale is comprised of 12 items which measure support received from family, friends and other people. Each item has 7 choices, ranging from 1 (very strongly disagree) to 7 (very strongly agree), and the highest score possible on the MSPSS is 84. A higher score reflects stronger social support. The mean score MSPSS of sample was 66.25 $(\mathrm{SD}=13.11)$. Cronbach alpha for the present sample was 0.71 .

Socio-demographic variables included gender ("female" coded as 0 and "male" coded as 1), age, whether in a love relationship currently or dating ("yes" coded as 1 and "no" recoded as 0 ), whether they had a religious belief ("yes" coded as 1 and "no" recoded as 0 ), marital status of parents (currently married was coded as 1; "divorced" and "widowed" combined with unmarried and coded as 0), life attitude ("very optimistic" coded as 3, "relatively optimistic" coded as 2, "pessimistic" coded as 1), school performance (which refers to the average school score students get in school, "A level" coded as 4, "B level" coded as 3 , "C level" coded as 2 , "D level" coded as 1 ), and time spent studying ("most of time" coded as 3, "frequent" coded as 2, "never" coded as 1). In addition, being satisfied with their major is relevant for Chinese students. In China, not all students are able to freely choose their preferred major, and they may be forced by the school to accept a major they do not like. Students were given two choices: "satisfied" (coded as 1) and "dissatisfied" (coded as 0 ).

The descriptive statistics for the sample are shown in Table 1. There were no differences by sex except that the females had a significantly higher grade point average than did the males.

\begin{tabular}{|c|c|c|}
\hline \multirow{2}{*}{ Variable } & Male & Female \\
\hline & $N(\%) / M \pm S D$ & $\mathrm{~N}(\%) / \mathrm{M} \pm \mathrm{SD}$ \\
\hline Gender & $499(38.4 \%)$ & 799 (61.6\%) \\
\hline Age & $19.86 \pm 2.106$ & $19.41 \pm 1.345$ \\
\hline \multicolumn{3}{|c|}{ Love/dating status* } \\
\hline Yes & $160(31.8 \%)$ & $224(27.4 \%)$ \\
\hline No & $339(68.2 \%)$ & $575(72.6 \%)$ \\
\hline \multicolumn{3}{|c|}{ Religion/religiosity* } \\
\hline Yes & $34(6.9 \%)$ & $66(8.3 \%)$ \\
\hline No & $461(93.1 \%)$ & $729(91.7 \%)$ \\
\hline \multicolumn{3}{|c|}{ Parents marital status* } \\
\hline Currently married & $447(91.6 \%)$ & $731(92.3 \%)$ \\
\hline other & $52(8.4 \%)$ & $68(7.7 \%)$ \\
\hline
\end{tabular}

\begin{tabular}{|c|c|c|}
\hline \multicolumn{3}{|l|}{ Life attitude* } \\
\hline very optimistic & $474(59.5 \%)$ & $315(63.1 \%)$ \\
\hline relatively optimistic & $297(37.3 \%)$ & $167(33.5 \%)$ \\
\hline pessimistic & $26(5.2 \%)$ & $17(3.4 \%)$ \\
\hline \multicolumn{3}{|c|}{ Satisfied with major* } \\
\hline satisfied & $444(89.0 \%)$ & 715 (90.9\%) \\
\hline unsatisfied & $55(11.0 \%)$ & $72(9.1 \%)$ \\
\hline \multicolumn{3}{|c|}{ School performance ${ }^{\#}$} \\
\hline A level & $37(9.6 \%)$ & $83(14.4 \%)$ \\
\hline B level & $196(50.8 \%)$ & $372(64.6 \%)$ \\
\hline C level & $112(41.0 \%)$ & $93(16.1 \%)$ \\
\hline D level & $41(10.6 \%)$ & $28(2.9 \%)$ \\
\hline \multicolumn{3}{|c|}{ Time spent on study* } \\
\hline most time & $357(75.3 \%)$ & $610(79.2 \%)$ \\
\hline frequent & $84(17.7 \%)$ & $109(14.2 \%)$ \\
\hline never & $58(13.0 \%)$ & $80(10.2 \%)$ \\
\hline Social support & $64.20 \pm 14.6$ & $67.53 \pm 11.9$ \\
\hline
\end{tabular}

Table 1: Characteristics of the sample by gender.

\section{Results}

Table 2 presents the association of the variables with depression scores. Depression scores were significantly higher in those with religious beliefs, a pessimistic attitude toward life, dissatisfaction with their major, rarely studying, if they were not dating or involved with another, and if they had less social support. There were no significant associations with depression scores from sex, age, parent's marital status or grade point average.

\begin{tabular}{|c|c|c|c|c|}
\hline \multirow{2}{*}{ Variable } & CES-D & \multirow{2}{*}{$F / t / r$} & \multirow{2}{*}{$\mathbf{P}$} & \multirow{2}{*}{$\begin{array}{l}\text { Effective } \\
\text { size }\end{array}$} \\
\hline & $(M \pm S D)$ & & & \\
\hline \multicolumn{2}{|l|}{ Gender } & 0.039 & 0.844 & 0 \\
\hline Female & $32.25 \pm 19.04$ & & & \\
\hline Male & $32.71 \pm 18.32$ & & & \\
\hline \multicolumn{2}{|l|}{ Age } & -0.036 & 0.198 & \\
\hline \multicolumn{2}{|c|}{ Love/dating status } & 4.624 & 0.032 & 0.006 \\
\hline Yes & $30.20 \pm 16.85$ & & & \\
\hline No & $33.28 \pm 18.76$ & & & \\
\hline \multicolumn{2}{|c|}{ Religion/religiosity } & 14.233 & $<0.001$ & 0.01 \\
\hline Yes & $38.74 \pm 20.46$ & & & \\
\hline
\end{tabular}


Page 3 of 4

\begin{tabular}{|l|l|l|l|l|}
\hline \multicolumn{2}{|l|}{$31.91 \pm 18.06$} & & & \\
\hline No Parents marital status & 0.137 & 0.712 & 0.001 \\
\hline Currently married & $32.24 \pm 18.21$ & & & \\
\hline Other & $34.27 \pm 19.42$ & & & \\
\hline Life attitude & $26.35 \pm 14.55$ & & $<0.001$ & 0.171 \\
\hline Very optimistic & $41.86 \pm 19.53$ & & & \\
\hline $\begin{array}{l}\text { Relatively } \\
\text { optimistic }\end{array}$ & $43.96 \pm 11.26$ & & & \\
\hline pessimistic & $31.86 \pm 18.06$ & & & \\
\hline Satisfied with major & $37.37 \pm 19.70$ & & 0.001 & 0 \\
\hline Satisfied & $31.35 \pm 17.26$ & & & \\
\hline Dissatisfied & $31.89 \pm 17.52$ & & & \\
\hline School performance & $29.98 \pm 17.53$ & & & \\
\hline A level & $28.87 \pm 16.31$ & & & \\
\hline B level & $33.20 \pm 18.59$ & & & \\
\hline C level & $33.01 \pm 18.84$ & & & \\
\hline D level & & & \\
\hline Time spent on study & & & \\
\hline Most time & & & \\
\hline Frequent & & & \\
\hline Never & & & \\
\hline Social support & & & \\
\hline
\end{tabular}

Table 2: The CES-D scores for important independent variable in the study.

In the multiple regression (Table 3), only religion, life attitude, satisfaction with one's major and social support remained as significant predictors of depression scores. The R2 was 0.26 , and the significant predictors are shown in bold type.

\begin{tabular}{|l|l|l|l|l|}
\hline Variable & Coefficient & SE & $\mathbf{t}$ & $\mathbf{p}$ \\
\hline Gender & 0.704 & 1.108 & 0.64 & 0.5 \\
\hline Age & -0.136 & 0.314 & -0.43 & 0.6 \\
\hline Love/dating status & 0.859 & 1.145 & 0.75 & 0.83 \\
\hline Religion/religiosity & -5.394 & 1.851 & -2.914 & 0.001 \\
\hline Marital status of parents & -1.891 & 2.303 & -0.82 & 0.5 \\
\hline Life attitude & -9.657 & 1.02 & -9.47 & $<0.001$ \\
\hline Satisfaction with major & -0.854 & 1.794 & 0.48 & $<0.001$ \\
\hline School performance & -0.552 & 0.889 & -0.62 & 0.53 \\
\hline Time spent on study & -0.263 & 1.086 & -0.24 & 0.1 \\
\hline Social support & -0.46 & 0.043 & -10.82 & $<0.001$ \\
\hline
\end{tabular}

\begin{tabular}{|l|l|l|l|l|}
\hline Constant & 102.599 & & & \\
\hline Note: R2=0.261
\end{tabular}

Table 3: Multivariable linear regression of relative variables on depression.

\section{Discussion}

The present study investigated depression in Chinese college students and the factors which may cause students to be depressed and protect them against depression. The results demonstrated that the variables of having an optimistic attitude toward life, being satisfied with one's major, and their level of social support were negatively associated with their depression scores, while having a religious belief was positively associated with depression scores. Gender had no significance influence on college students depression scores even though the female students had higher grade point averages than did the male students.

Interestingly, students who had religious beliefs compared were more likely to be depressed. Only $8.3 \%$ of the women and $6.9 \%$ of the men reported having religious beliefs and, while research in Western nations has shown that religion has a positive effect on a variety of indicators of well-being [22], happiness [23], and life satisfaction [24] as well as suicide [25], having religious beliefs is not the norm and may cause stress for religious students. Alternatively, perhaps the more depressed students are more likely to adopt religious beliefs.

The results also indicated that the more time the students spent on study, the lower the depression scores of the students. It may be that students who do not study much experience guilt and a lower sense of accomplishment. It may also be that students who are already depressed find it more difficult to study diligently, setting up a vicious cycle.

The results also indicated that social support has an impact on depression. The more social support the students reported, the lower their depression scores. As previous research has demonstrated, social support acts as a protective factor, reducing the chance of major stressors provoking clinical depression or other forms of psychopathology or illness [26]. Social support is an important factor in promoting health and well-being.

Depression among university students in China is a major concern, and several recent studies have searched for risk factors including gender and stressful life events [27], rumination [28] and Internet addiction [29], and several investigations have been conducted on ways of helping university student's deal with their depression, such as dialectical behavior therapy [30].

\section{Limitations}

Since the present study focused on college students, the results may not apply to the general population in China. However, depression and suicidal behavior is of great concern to Chinese university administrators who make a strong effort to monitor the well-being of their students. Another limitation of this study is that there may be many other factors that could affect depression in students, such as the social economic status of the students' families and their life experiences. Finally, the problem of cause-and-effect could not be studied in this cross-sectional study. Long-term follow-up studies could throw light on the cause and effect issue. 


\section{Conclusion}

Future research should explore the associations found in the present study in other groups of students, for example, in vocational schools and high schools. University students in China are subject to a variety of constraints in addition to not having complete freedom in their choice of academic major, such as monitoring their location on the campus. The impact of this authoritarian control would an important focus for subsequent research.

\section{References}

1. Kadison R, DiGeronimo TF (2004) College of the overwhelmed: The campus mental health crisis and what to do about it. Jossey-Bass.

2. Taub DJ, Robertson J (2013) Preventing College Student Suicide: New Directions for Student Services, Number 141. John Wiley \& Sons.

3. ACHA (2012) American College Health Association-National College Health Assessment II: Reference Group Executive Summary Fall 2011. American College Health Association.

4. Holden C (2000) Global survey examines impact of depression. Science 288: 39-40.

5. Rosselló J, Bernal G (1999) The efficacy of cognitive-behavioral and interpersonal treatments for depression in Puerto Rican adolescents. J Consult Clin Psychol 67: 734.

6. Romaniuk M, Khawaja NG (2013) University student depression inventory (USDI): Confirmatory factor analysis and review of psychometric properties. J Affect Dis 150: 766-775.

7. Short MA, Gradisar M, Lack LC, Wright HR (2013) The impact of sleep on adolescent depressed mood, alertness and academic performance. J Adol 36: 1025-1033.

8. Michl LC, McLaughlin KA, Shepherd K, Nolen-Hoeksema S (2013) Rumination as a mechanism linking stressful life events to symptoms of depression and anxiety: Longitudinal evidence in early adolescents and adults. J Abnorm Psychol 122: 339-352.

9. Angst J, Gamma A, Gastpar M, Lépine JP, Mendlewicz J, et al. (2002) Gender differences in depression. Eur Arch Psychiatry Clin Neurosci 252: 201-209.

10. Pacini R, Epstein S (1999) The relation of rational and experiential information processing styles to personality, basic beliefs, and the ratiobias phenomenon. J Pers Soc Psychol 76: 972-987.

11. Cummings CM, Caporino NE, Kendall PC (2014) Comorbidity of anxiety and depression in children and adolescents: 20 years after. Psychol Bull 140: 816-845.

12. Lee S (1999) Diagnosis postponed: shenjing shuairuo and the transformation of psychiatry in post-Mao China. Cult Med Psychiat 23: 349-380.

13. Kim KI, Won H, Liu X, Liu P, Kitanishi K (1997) Students' stress in China, Japan and Korea: A transcultural study. Int J Soc Psychiat 43: 87-94.
14. Wang Y, Kim SY (2013) Acculturation and Culture: A Critical Factor for Asian Americans' Health. In Handbook of Asian American Health. Springer, pp: 137-154.

15. Kleinberg A, Aluoja A, Vasar V (2013) Social support in depression: structural and functional factors, perceived control and help-seeking. Epidemiol Psychiat Sci 22: 345-353.

16. Cheng C (1997) Role of perceived social support on depression in Chinese adolescents: A prospective study examining the buffering model. J App Soc Psychol 27: 800-820.

17. Lee Y (2014) The relationship of spiritual well-being and involvement with depression and perceived stress in Korean nursing students. Glob J Health Sci 6: 169.

18. San Martín J, Perles F, Canto JM (2010) Life satisfaction and perception of happiness among university students. Span J Psychol 13: 617-628.

19. Radloff LS (1977) The CES-D scale: A self-report depression scale for research in the general population. App Psychol Meas 1: 385-401.

20. Zimet GD, Dahlem NW, Zimet SG, Farley GK (1988) The multidimensional scale of perceived social support. J Pers Assess 52: 30-41.

21. Zhang J, Norvilitis JM (2002) Measuring Chinese psychological wellbeing with Western developed instruments. J Pers Assess 79: 492-511.

22. Aitaoto N, Braun KL, Dang KOL, So aT (2007) Cultural considerations in developing church-based programs to reduce cancer health disparities among Samoans. Ethnicity and Health 12: 381-400.

23. Abdel-Khalek AM, Lester D (2018) Subjective well-being and religiosity: significant associations among college students from Egypt and the United Kingdom. Int J Cult Ment Health 11: 332-337.

24. Markides KS, Levin JS, Ray LA (1987) Religion, aging, and life satisfaction: An eight-year, three-wave longitudinal study. The Gerontologist 27: 660-665.

25. Lester D (2017) Does Religiosity Predict Suicidal Behavior? Religions 8 238.

26. Brown GW, Andrews B (1986) Social support and depression. In Dynamics of stress. Springer, pp: 257-282.

27. Sun XJ, Niu GF, You ZQ, Zhou ZK, Tang Y (2017) Gender, negative life events and coping on different stages of depression severity: A crosssectional study among Chinese university students. J Affect Disord 209: 177-181.

28. Liang H, Chen C, Li F, Wu S, Wang L, et al. (2018). Mediating effects of peace of mind and rumination on the relationship between gratitude and depression among Chinese university students. Curr Psychol, pp: 1-8.

29. Nie J, Zhang W, Liu Y (2017) Exploring depression, self-esteem and verbal fluency with different degrees of internet addiction among Chinese college students. Compr Psychiatry 72: 114-120.

30. Cheng PH, Merrick E (2017) Cultural adaptation of dialectical behavior therapy for a Chinese international student with eating disorder and depression. Clinical Case Studies 16: 42-57. 